\title{
O Comércio Justo como movimento social para obtenção da Justiça Global
}

\author{
Joana Stelzer*
}

Alexandre Pinto Moreira**

\section{Resumo}

Sob a perspectiva das Teorias de Justiça Global analisam-se as relações solidárias que surgem das desigualdades resultantes da globalização. Inicialmente tem-se uma abordagem para identificar algumas teorias existentes relativas ao conceito de Justiça. Na continuidade, aborda-se a teoria de John Rawls, Nussbaum, Beitz e Pogge. Com este fundamento teórico tem-se os elementos necessários para se contextualizar o Comércio Justo como movimento social que se adequa à busca de Justiça Global. A investigação implica pesquisa qualitativa, servindo-se do meio bibliográfico e legislação. O método de abordagem utilizado é o hipotético dedutivo e, quanto aos fins, trata-se de análise descritiva.

Palavras-Chave: Comércio Justo; Movimento Social; Justiça Global; Globalização; Desigualdade

\section{The Fair Trade as a social movement to obtain the Global Justice}

\begin{abstract}
From a perspective of Global Justice Theories examines the solidarity relations that arise because of inequalities resulting from globalization. Initially we have an approach to identify some existing theories that work the concept of justice. John Rawls's theory is first studied, and then Nussbaum, Beitz, and Pogge. With this theoretical foundation we have the necessary

\footnotetext{
* Doutora e Mestre em Direito pela Universidade Federal de Santa Catarina (UFSC). Coordenadora do Núcleo de Extensão em Fair Trade/Comércio Justo (NEFT/UFSC). Professora credenciada no Programa de Pós-Graduação em Direito da Universidade Federal de Santa Catarina (PPGD/CCJ/UFSC). Email: joana.stelzer@ufsc.br

** Mestre em Direito pela Universidade Federal de Santa Catarina (PPGD/CCJ/UFSC). Professor das Faculdades de Direito da Universidade Estadual Vale do Acaraú e Faculdade Luciano Feijão. Professor da Escola Superior do Ministério Público do Estado do Ceará. Especialista em Processo Judicial pela UVA-CE e em Direito Constitucional e Processo Constitucional pela UECE-ESMP. Email: alexandrepinto1@globo.com
} 
elements to contextualize the Fair Trade as a social movement that fits the search for Global Justice. The Research implies qualitative research, using the literature and legislation. The method of approach used is the hypothetical deductive and, for purposes, it is descriptive analysis.

Key words: Fair Trade; Social Movement; Global Justice; Globalization; Inequality

\section{Introdução}

Embora a globalização tenha diminuído fronteiras reais entre os mais diversos pontos do planeta, não se deve olvidar que também instalou modelo econômico responsável por aumento das desigualdades sociais e regionais. $\mathrm{O}$ avanço dessas desigualdades determinou o aprofundamento dos estudos de filósofos e juristas sobre a necessidade de se definirem critérios que pudessem representar a existência de um modelo de justiça, capaz de ser utilizado indistintamente no planeta, denominado Justiça Global.

Entre as possibilidades de superação das graves injustiças que caracterizam a realidade mundial emerge o Comércio Justo, na qualidade de fenômeno que envida esforços para comercializar produtos de organizações preocupadas com os produtores (embora não somente com eles), especialmente de países do Sul, para alterar injustas estruturas do comércio mundial, caracterizado pelo comando de poucas empresas transnacionais e que levam à ruína pequenos agricultores de todo o mundo. Sob tal contexto, os consumidores são convidados a participar do movimento à medida que impulsionam a relação negocial e podem transformar o ato de consumo em ato político de inclusão social.

A problematização do presente estudo defronta-se com a seguinte indagação: tendo em vista a Teoria da Justiça Global e especialmente pela magnitude de seu alcance, o Comércio Justo pode ser considerado uma ferramenta de concretização desse ideal? Com efeito, o Comércio Justo envolve mudanças comportamentais importantes rumo à sociedade equânime em respeito à dignidade humana, ao propor inovadora conduta comercial, justo preço, transparência e informação na cadeia logística, educação para o consumo ético, entre outros. Sob tal motivação, foram considerados objetivos do presente estudo: descrever a proposta denominada Justiça Global, apontando suas principais propostas; identificar o 
Comércio Justo como ferramenta de concretização da Justiça Global; e, destacar a importância do consumo (e do consumidor) enquanto possível ato político de inclusão.

A investigação justifica-se em virtude das graves injustiças que assolam largas camadas da população mundial e clamam por alternativas viáveis, motivos que exigem reflexão acadêmica e política sobre o assunto, na busca de valores e critérios voltados à promoção e ao reconhecimento de práticas de Comércio Justo e Solidário. Com isso, será possível avaliar a Teoria da Justiça Global, além dos desafios e das convergências dessa proposta.

O marco teórico possui vertentes diferenciadas e que se aproximam em muitos momentos, embora não se pacifiquem do ponto de vista ideológico. Dentre os estudiosos, John Rawls merece destaque a partir da obra A Theory of Justice, embora no presente estudo tenha ganhado ênfase a obra The Law of Peoples. Considerado o precursor dos princípios da Justiça Global, influenciou autores como Pogge, Beitz e Nussbaum que também são pontuados nesta investigação. Enquanto Pogge e Beitz defendem o Pacto Global que é devidamente estabelecido por instituições consolidadas com o intuito de se garantir uma lista de direitos humanos básicos para todos os indivíduos, Nussbaum avalia de forma otimista a teoria de Rawls e debate a necessidade de fornecer a todas as pessoas (em especial as de mais baixa renda) a oportunidade de escolher seus próprios caminhos de acordo com suas habilidades e vocações.

Finalmente, avalia-se o Comércio Justo a partir da Justiça Global e sob ótica específica de movimento social que busca a redução das desigualdades sociais privilegiando a aquisição de produtos do Sul que são produzidos com respeito ao meio-ambiente, às leis trabalhistas e às relações de gênero. Igualmente, é dada ênfase ao consumidor, por entender o relevante papel que esse tem para realização da Justiça Global. Afinal, é no consumo associado ao Comércio Justo que efetivamente se pode alcançar um ato de justiça.

O método utilizado foi o hipotético-dedutivo, com a avaliação dos dados e teorias sob abordagem qualitativa. Os meios utilizados foram predominantemente bibliográficos, com presença de dados estatísticos secundários, além de legislação. Quanto aos fins, a pesquisa apresenta-se de cunho descritivo com os resultados expostos exclusivamente em forma de textos.

Revista Cidadania e Acesso à Justiça | e-ISSN: 2526-026X | Maranhão | v. 3 | n. 2 | p. 39 - 60 | Jul/Dez. 2017. 


\section{A globalização e a distribuição de riquezas}

Considerando a progressiva facilidade de interação entre os diversos países do planeta e o sistema capitalista dominante no que diz respeito à distribuição de riquezas, é cada vez mais comum a instalação de filiais de grandes empresas transnacionais em países considerados subdesenvolvidos ou em desenvolvimento. Em geral, tais companhias, visando à obtenção de maior lucro para suas atividades, consideram destacados fatores na busca por novos territórios para a instalação de filiais. Nesse sentido, pode-se citar a procura por mão de obra pouco qualificada e, acima de tudo, pouco onerosa; incentivos do Poder Público desses países; e, fragilidades e lacunas nas leis, em geral. Desse modo, bem-estar e dignidade dos empregados dessas organizações transnacionais, em geral, não são prioridade. Ademais, sob o argumento de proporcionar impulso na economia nacional, tais corporações não exploram apenas o elemento humano, mas também riquezas naturais. Em síntese, além de pouco contribuírem para o bem-estar social, ainda degradam o meio-ambiente.

Mas, à parte dos efeitos nocivos promovidos pela globalização, cumpre registrar aspectos positivos acarretados pela força desse fenômeno. Sob tal auspício, registrem-se as redes empenhadas em solidariedade e que também passaram a se relacionar mundialmente, no intuito de ajudarem seres humanos à existência digna. A tecnologia da informação (TI) tornou-se ferramenta indispensável para a implantação efetiva dos processos de reestruturação socioeconômica. De especial importância foi o papel da TI para possibilitar a formação de redes de modo dinâmico e auto-expansível. Essa lógica preponderante de redes transforma todos os domínios da vida social e econômica (CASTELLS, 2011, p. 41).

É na rede que Castells (2011) aposta sua esperança, pois a sociedade pode escrever novamente sua história. Os cidadãos estão multiplicando as maneiras colaborativas de trocas, sem se tornarem dependentes dos valores do neoliberalismo, a exemplo de suposta eficiência proporcionada pelas corporações transnacionais. O próprio conceito de Estado-Rede, para Castells (2011), fez que se verificassem mudanças no espaço mundial e a derrocada da estratificação vertical que caracteriza o tempo contemporâneo rumo à horizontalidade das relações econômicas, sociais, tecnológicas, entre outras. (STELZER; GONÇALVES, 2014). Sob tal lógica, segue o fenômeno intitulado Comércio Justo.

\section{O Mundo e suas desigualdades}


Como evidenciado, o mundo interligado em uma imensa rede possui aspectos tanto positivos quanto negativos. Com uma maior proximidade entre diferentes países, ficam evidenciadas as imensas disparidades existentes, principalmente quando se revelam em paralelo as nações do Norte desenvolvido e do Sul subdesenvolvido (ou, em desenvolvimento), nos mais variados quesitos.

\begin{abstract}
A globalização econômica conduziu a saltos econômicos na China e em outros lugares e, como consequência, levantou centenas de milhões de pobreza extrema para um padrão de vida decente. Mas, também implicou a ampliação das lacunas globais e a comercialização e privatização de serviços sociais e instituições com algumas implicações nocivas. (COLLSTE, 2006, p. 43)
\end{abstract}

Um dos indicadores mais relevantes para mensurar o nível de desenvolvimento de cada país é o Índice de Desenvolvimento Humano (IDH). O IDH é uma escala, entre zero e um, que considera fatores relacionados à renda per capita, à longevidade e ao acesso à educação da população de determinado Estado. O IDH brasileiro, por exemplo, é de 0,754, conforme balanceamento de 2015, ocupando a 79a posição no ranking mundial. Considera-se, entretanto, Níger, a título comparativo, um país da África Subsaariana, que possui um dos menores índices de desenvolvimento humano do mundo (0,353 em 2015) e, por outro lado, a Noruega, país rico da Europa, líder do ranking mundial, com um IDH 0,949 em 2015 (ODES, 2015).

Em caso de análise a partir unicamente do fator econômico, por meio da renda per capita, índice pelo qual se divide o Produto Interno Bruto pela população total de determinado país, a diferença torna-se mais chocante. Utilize-se como exemplo as mesmas nações acima mencionadas: Níger, com Produto Interno Bruto (PIB) de US\$7,14 bilhões (2015) (valor que pode ser equiparado ao de Caxias do Sul, município do Rio Grande do Sul) e aproximadamente vinte milhões de habitantes; e, Noruega, com PIB de US\$386,58 bilhões e população de aproximadamente cinco milhões de residentes (2015).

Calculando, assim, a renda per capita, obtém-se: Noruega beirando os cem mil dólares por habitante e Níger com um valor inferior a quatrocentos dólares por habitantes (TRADINGECONOMICS, 2015). É válido ressaltar, ainda, que tais números servem apenas como base de comparação, uma vez que não consideram a distribuição de renda entre os habitantes do mesmo país. Ou seja, além de o Estado ser pobre, ainda há uma grande 
possibilidade de as poucas riquezas serem mal distribuídas e de boa parte da população viver em condições miseráveis.

Conforme relatório do Programa das Nações Unidas para o Desenvolvimento, com dados de 2015, ainda existem 766 milhões de pessoas vivendo com menos de 1,90 dólar por dia (TRADINGECONOMICS, 2015). No mesmo balanço, o Brasil foi considerado o décimo país mais desigual do planeta e ficou constatado, também, que 1\% da população mais rica do mundo concentra, em suas mãos, $46 \%$ da riqueza global. Tal situação descrita evidencia a desigualdade quando se possui como referência o aspecto econômico, mas também deve ser ressaltado que há ainda as questões das desigualdades decorrentes de relações de trabalho, de gênero, de orientação sexual, de raça, etnias, ente outras.

Com o intuito de serem diminuídas essas desigualdades é que surgiu um movimento em todo o mundo que pode ser denominado de Justiça Global, que possui os fundamentos teóricos em autores que procuram aproximar o movimento social de conceitos acerca da Justiça, com ênfase nos direitos humanos e no meio-ambiente, os quais se passam a descrever.

\section{Justiça Global em Perspectiva}

Considerando o contexto atual de um mundo globalizado e todo tipo de desigualdade econômica e social proveniente dessa causa, a solução para uma contrapartida que visasse beneficiar os que mais precisam e que, principalmente, buscasse propiciar uma melhor distribuição das riquezas do globo fez crescer o debate acerca da ética social em escala mundial. Dessa forma, desenvolveu-se a teoria da Justiça Global que propõe, entre outras atribuições e áreas de atuação, uma avaliação dos benefícios e encargos das relações estruturais e institucionais que constituem e manejam a globalização (COLLSTE, 2016, p. 8).

É preciso alertar que países como o Brasil (além de outros países subdesenvolvidos ou em desenvolvimento) teriam vantagens com a efetivação de uma Justiça Global. Contudo, verifica-se baixo engajamento nessa perspectiva. Os estudos, até então, concentram-se - em sua maioria - na Europa e nos Estados Unidos. Sob tal ótica, não somente cumpre registrar a importância do assunto, quanto revelar novel perspectiva. Sob tal desiderato, John Rawls é considerado um dos mais relevantes precursores do estudo dos princípios da Justiça Global, desde sua obra A Theory of Justice, de 1971. Desde então, o assunto atrai adeptos e, também, críticos. No entanto, analisa-se a proposta de Rawls para explicar a origem das desigualdades 
globais, em seu livro The Law of Peoples (1999), quando menciona que o primeiro decide industrializar enquanto o segundo nada decide. Satisfeito com as coisas como elas estão e preferindo uma sociedade menos complexa e com mais apoio social, o segundo reafirma seus valores sociais (RAWLS, 1999, p. 117).

Acerca do tema e contrastando a visão de Rawls, Thomas Pogge (2002; 2005), autor e filósofo alemão, diretor do Programa de Justiça Global, propõe sua própria teoria de uma “ordem institucional global” (COLLSTE, 2016). Conforme entendimento de Pogge, existe uma aliança entre os países ricos do norte industrializado com alguns governos autoritários de países emergentes e interesses empresariais globais que sustentam tal ordem institucional, tornando permanente a desigualdade entre as parcelas mais ricas e mais pobres do planeta.

Dessa forma, emerge a existência de 'privilégios de recursos internacionais', tornando possível que governantes corruptos de países considerados em desenvolvimento controlem o fornecimento de seus recursos para empresas transnacionais sem quaisquer escrúpulos, enriquecendo ainda mais os abastados e em nada ajudando ou, pior, atrapalhando as pessoas pobres dessas nações (POGGE, 2002, p. 199).

Pogge (2002) aduz, ainda, que essa imposição de uma ordem institucional global atinge a todos, o que dá plena capacidade de tentar imaginar, idealizar e propor uma alternativa. Ocorre que, para tal, necessita-se, inclusive, do esforço e da anuência daqueles que são beneficiados com a atual ordem. Conforme o que prega em seu livro Real World Justice (2005):

\footnotetext{
Minha principal alegação é então que, ao moldar e fazer cumprir as condições sociais que previsível e evitavelmente causam o sofrimento monumental da pobreza global, estamos prejudicando os pobres globais - ou para colocá-lo de forma mais descritiva, somos participantes ativos no maior, e mais grave, crime contra a humanidade já cometido. (POGGE, 2005, p.33)
}

Nesta passagem, Pogge (2005) procura deixar explícito que, ao passo em que nada se faz e todos se mantêm neutros acerca do sofrimento dos mais necessitados em um mundo extremamente desigual, estar-se-ia contribuindo ativamente para o maior e mais grave crime contra a humanidade já cometido.

Outra visão importante, que não se pode deixar de discutir neste trabalho, é a de Martha Nussbaum cuja obra, procura promover a discussão da Justiça Global partindo de outra perspectiva: the capabilities approach (ou abordagem de capacidades), que considera as 
necessidades e direitos básicos de todo e qualquer ser humano como o mínimo que a justiça deveria requerer e promover para todos (NUSSBAUM, 2004, p. 4).

\subsection{O Pacto Global de Beitz e Pogge}

Ao se aprofundar no tema da Justiça Global acaba-se por tomar como referência o pensamento de outro estudioso do tema e também da obra de Rawls. Trata-se de Charles Beitz (2012), professor e teórico político norte americano. Além do já referido Thomas Pogge, nas obras desses autores, há a proposta de nova teoria acerca da abordagem contratual: the global bargain, ou, no português, pacto global.

Sob a ótica desses pensadores, a maneira correta de desenvolver a teoria de Rawls acerca de uma Justiça Global seria considerando a ideia de posição originária aplicada ao mundo como um todo (NUSSBAUM, 2004, p. 10). Para tal, a priori, dever-se-ia ampliar o acesso à justiça visando considerar cada indivíduo do planeta como sujeito de justiça. Em outras palavras, os mais diversos partidos e grupos políticos espalhados pelo mundo deveriam negociar e realizar acordos já considerando uma imensa estrutura global que, por sua vez, deveria alcançar a totalidade da população mundial. Desta maneira, Pogge e Beitz acreditam que essa nova composição seria benéfica para a posição dos menos favorecidos.

Sendo desenvolvida essa nova estrutura global, Pogge (2002) propõe uma “especulação ilustrativa” no qual prevê um primeiro acordo global, que apresentaria uma lista de direitos humanos, bem mais robusta do que a indicada por Rawls. Para Pogge (2002; 2005), deveriam ser acrescentadas à Declaração Universal dos Direitos Humanos normas que garantissem o direito de migração, bem como uma adequada redistribuição dos recursos naturais. Argumenta o filósofo que, no decorrer dos anos, cada vez mais princípios seriam adicionados, incluindo, inclusive, restrições econômicas globais. Entretanto, uma imensa dificuldade que deve ser considerada ao tentar imaginar a aplicação das teorias de Pogge e Beitz, na prática, é o caráter dinâmico da atual ordem mundial. Afinal, a estrutura global a ser considerada pelos partidos políticos - ao passo em que realizam seus negócios e acordos está em constante mutação.

Acredita-se que, por muitas vezes, os grupos políticos não conseguem acompanhar o ritmo dessas mudanças, o que, de certa forma, atrasaria e atrapalharia o andamento de um eventual pacto global. Além do mais, nesse caso considerar-se-iam apenas os grupos que 
iriam 'querer', mas não conseguiriam seguir essas transformações sem analisar, no entanto, aqueles mais conservadores que não concordariam e optariam por não seguir.

Acima de tudo, seria necessário colocar de lado algumas divergências de caráter meramente político e levar em consideração o bem comum e a qualidade de vida daqueles mais necessitados. Os partidos políticos deveriam, por sua vez, conhecer as particularidades de suas nações, em especial no que tange à economia, às relações comerciais, ao fluxo de informações, à presença de agências e tratados internacionais, entre outras. Conhecendo as peculiaridades, as riquezas e objetivando unicamente o desenvolvimento econômico e social de seus países, bem como a comunhão e o respeito humano, os partidos políticos conseguiriam, de forma mais eficaz, negociar e realizar acordos e tratados que propiciassem, verdadeiramente, vantagens mútuas, e não beneficiassem apenas as partes mais poderosas. Não se deixa de reconhecer de forma crítica essa concentração dos objetivos para atingir uma Justiça Global nos partidos políticos ante a diversidade de características que possuem, tendo em vista a realidade política dos países que fazem parte.

\subsection{A Cooperação Social e a Abordagem das Capacidades de Nussbaum}

Mesmo já tendo sido mencionada anteriormente, Martha Nussbaum possui um trabalho que não pode deixar de ser explorado, conforme artigo Beyond the Social Contract: Capabilities and Global Justice (2004), cuja importância para o desenvolvimento de uma Justiça Global é de suma importância.

De plano, a autora explica não serem completamente justos, ou pelo menos não para grande parte da população mundial, os acordos de vantagens mútuas celebrados entre países e/ou partidos políticos à luz dos modelos de Kant, amplamente defendidos por Rawls. Para a estudiosa, o instituto da cooperação social deve ser interpretado como algo muito maior e mais abrangente do que o proposto por Rawls, considerando, inclusive, a tradição da lei natural pré-contratualista. Para tal, Nussbaum (2004) aproxima-se de Grotius e aduz que os humanos são seres que, em geral, desejam viver na coletividade. Ademais, defende que é inerente à realidade humana a vontade de coabitar com os semelhantes um mundo moralmente decente em que todos tenham igual acesso a uma vida minimamente digna. Dessa forma, todo e qualquer cidadão poderia dispor e optar, de acordo com suas capacidades, por seguir seus mais variados caminhos. É nessa possibilidade de escolha por parte de todos os 
homens e mulheres que reside o ponto central da abordagem das capacidades. A autora aduz que no âmbito doméstico de cada país, seria esse fator que as instituições deveriam garantir aos seus administrados e, igualmente, representar a maior reivindicação geral do povo em relação aos seus líderes.

$\mathrm{Na}$ esfera internacional, por outro lado, deve-se visar uma situação diferente e esbarraria na soberania de cada Estado. Entretanto, a abordagem das capacidades sugere uma lista de direitos humanos, tal como a proposta de Pogge, a ser seguida pelos cidadãos de todas as sociedades, desde que essas sejam minimamente justas. A lista mencionada deveria basearse nos pré-requisitos mais fundamentais para a manutenção de uma vida digna para todo ser humano. Nessa ótica, estariam nutrição adequada, acesso à educação de qualidade, proteção à integridade física e moral, bem como à liberdade de expressão e de culto.

O objetivo da abordagem das capacidades, conforme aduz Nussbaum, é fornecer a todas as pessoas (em especial as de mais baixa renda) a oportunidade de escolher seus próprios caminhos de acordo com suas habilidades e vocações. Dada essa chance, cada um aproveita da forma que julgar melhor para si e para sua família.

\footnotetext{
Embora a abordagem permaneça focada na pessoa como objetivo e está comprometida em assegurar os bens básicos da vida para cada um, diz respeito às mais variadas diferenças culturais: no papel atribuído às nações para implementação e especificação mais concreta da lista; Deve-se dar uma proeminência, nesta lista, às principais liberdades do discurso e da consciência. E, na ideia de que a capacidade é o objetivo político apropriado - eis que uma vez uma oportunidade é dada às pessoas, elas podem escolher o que fazer com isso. (NUSSBAUM, 2004, p.13)
}

Contextualmente, ainda consoante a visão da autora, não se pode confundir crescimento econômico e desenvolvimento humano ou social. É fato que se vive em um mundo de desigualdades, uma vez que a riqueza de determinado país não necessariamente implica adequada distribuição de renda entre sua população. Assim o Brasil, país que retrata péssima repartição de riquezas, embora assuma o décimo lugar no ranking do Programa das Nações Unidas para o Desenvolvimento de riqueza. Dito de outro modo, vive-se em um país economicamente rico e desigual, no qual grande parcela dos compatriotas é pobre ou miserável, com renda para - no máximo - sustentar a própria família.

Entretanto, para possibilitar a aplicação da teoria de Nussbaum, necessita-se de uma ação conjunta entre os cidadãos globais e as instituições que representam essas nações. Para tal, precisa-se atribuir deveres a esses órgãos e organizações governamentais. No que diz 
respeito à justiça, o fortalecimento com decência das instituições propiciaria melhor e mais eficaz atuação dos órgãos legislativos, executivos e judiciários, bem como dos Ministérios Públicos, na elaboração, aplicação e fiscalização de leis. Os ordenamentos jurídicos passariam a corresponder unicamente à necessidade da população em geral, colocando em segundo plano os interesses dos grandes empresários.

Dessa feita, às instituições estaria atribuída a responsabilidade de promover o bemestar social, bem como a igualdade de oportunidades e a capacidade de o cidadão dispor acerca de seu próprio futuro. Para que isso fosse viável, caberiam às estruturas institucionais impor aos seus respectivos povos, de maneira justa, o dever de respeitar e apoiar as aspirações de terceiros.

\footnotetext{
As normas éticas internas de cada religião ou doutrina ética determinará até que ponto cada pessoa é eticamente responsável por fazer mais do que é requerido institucionalmente; mas o ônus politico de fornecer suporte ao limite das capacidades é delegado às instituições. (NUSSBAUM, 2004, p.15)
}

Nessa passagem, a autora trata sobre o importante papel das doutrinas éticas e religiosas na defesa das capacidades das pessoas. Obviamente, todos são obrigados a cumprir apenas o que a lei determina, mas é fato que os preceitos e ensinamentos religiosos têm grande influência no pensamento de seus seguidores. Continuando o raciocínio, Nussbaum (2004) considera não ser desejável a criação de um hipotético Estado Global, em especial por se tratar de uma estrutura muito vasta que, provavelmente, não ofereceria uma adequada e suficiente prestação de contas aos seus cidadãos, não sendo possível um direito que se aplicasse de forma global oriundo desse Estado.

Ademais, é preciso sempre considerar que as mais variadas diferenças entre os povos, sejam elas culturais, religiosas ou até mesmo linguísticas, tornariam a comunicação muito difícil. Considere-se o exemplo da África, cuja demarcação dos países fora realizada por estrangeiros que simplesmente ignoraram a imensa gama de tribos e povos que habitavam aquele continente. O resultado disso foi, em geral, a eclosão de sangrentas guerras civis em vários territórios. Para a autora, a soberania nacional tem um papel fundamental para a viabilização do sistema proposto pela teoria da abordagem das capacidades. Tal importância fica evidenciada quando a presença de um Estado soberano oferece aos cidadãos nacionais um caminho por meio do qual podem legislar e reivindicar seus direitos e os de terceiros. 
Por fim, Nussbaum (2004) prega, ainda, que uma estrutura institucional decente em esfera mundial deveria ocorrer de forma descentralizada. Essa composição atribuiria às estruturas básicas domésticas, por sua vez, a responsabilidade de, inicialmente, redistribuir parte de suas riquezas a nações mais pobres e menos desenvolvidas. Ademais, outra parte dessa estrutura institucional cobraria das grandes empresas transnacionais a responsabilidade de promover as capacidades humanas nos países em que atuassem. Órgãos de atuação mundial também estariam inclusos nesse arranjo, dentre os quais o Banco Mundial, o Fundo Monetário Internacional, a Organização Mundial do Comércio, que visariam à implementação de novas políticas econômicas globais por meio de agências, acordos e tratados comerciais.

A atuação da Organização das Nações Unidas, da Organização Internacional do Trabalho, do Tribunal Mundial e do Tribunal Penal Internacional também é colocada pela autora como imprescindível para a promoção dos direitos humanos, do trabalho e para a preservação do meio ambiente nas mais diversas localidades do globo. As organizações nãogovernamentais, desde aquelas que atuam em pequenas localidades até as de cunho multinacional, também teriam sua importância nesta estrutura internacional. Para finalizar o estudo acerca da abordagem das capacidades de Nussbaum, enumeram-se os dez princípios da Justiça Global propostos pela autora em seu trabalho (2004, pp. 16-17).

Em primeiro lugar, Nussbaum propõe a sobredeterminação de responsabilidade, que exigiria, das nações mais pobres, o máximo empenho possível no tocante à diminuição das desigualdades sociais. Nesse sentido, aduz que a justiça só será satisfeita quando as instituições daqueles países consigam fornecer e promover meios pelos quais seus cidadãos possam desenvolver e desempenhar suas capacidades. No segundo princípio, reforça sua visão acerca da manutenção da soberania nacional dentro do território dos países no desenvolvimento das capacidades humanas. Para ela, há pouquíssimos casos que justifiquem uma intervenção coercitiva, tais como sanções econômicas e militares, de outros Estados na soberania de uma nação. Por outro lado, a persuasão e aplicação de investimentos seriam boas ideias, ou seja, a mitigação de soberania em decorrência da globalização só seria possível se atingisse o intuito de diminuir as desigualdades sociais.

O terceiro princípio traz uma ideia também já abordada, relativa à responsabilidade dos países ricos fornecerem uma parte de seu Produto Interno Bruto (PIB) para as nações mais pobres. Ao mesmo tempo a autora questiona para quem poderiam ser destinadas essas 
riquezas: se para os próprios governos ou se para organizações não-governamentais. O importante seria fornecer ajuda de forma eficiente para esses países sem, no entanto, ferir suas respectivas soberanias nacionais. É importante que se pontue a importância das organizações que constituem redes de colaboração solidárias e que poderiam ser utilizadas para o justo repasse dessas riquezas àqueles que realmente necessitassem.

O quarto princípio traz à tona a discussão acerca da função social das corporações transnacionais nos países em que atuam. Nussbaum sugere que essas grandes empresas passassem a investir e destinar parte de seus lucros à promoção da educação e da preservação das riquezas naturais dessas nações. Aqui, um ponto extremamente delicado dessa teoria, pois atinge o núcleo financeiro responsável pela movimentação dos mercados globalizados. De fato, percebe-se exatamente o contrário, ou seja, a falta de compromisso dessas corporações no tocante ao meio-ambiente, às relações justas de trabalho e ao pagamento justo pelo que é produzido.

Dessa forma, fica claro que a atuação das empresas transnacionais é de fundamental importância na promoção da Justiça Global nos países em que operam. Para tal, além de promover auxílios às populações locais, devem oferecer, também, boas condições de trabalho aos seus empregados, não se limitando apenas às exigências (muitas vezes falhas e cheias de lacunas) das legislações trabalhistas daqueles Estados. A ausência desse processo educativo é facilmente percebida até mesmo quando os autores que tratam do tema da Justiça Global reclamam da dificuldade de encontrar estudiosos do Sul pesquisando sobre essa temática. Alega-se um baixo interesse em virtude dos resultados danosos que pode trazer ao status quo do mercado financeiro.

O quinto princípio trata das principais estruturas econômicas mundiais, dentre as quais o Fundo Monetário Internacional e acordos comerciais gerais a nível global. Para a pesquisadora, deve-se considerar - por meio de reflexões éticas - a posição de hipossuficiência dos países pobres e em desenvolvimento ao serem concebidas tais estruturas.

No sexto princípio, Nussbaum propõe o desenvolvimento de instituições públicas globais que, embora viessem a atuar de forma descentralizada, fossem dotadas de uma eficiência vigorosa. Dentre as propostas, a autora cita a efetiva atuação de um tribunal penal mundial para lidar com graves violações dos direitos humanos, bem como um conjunto de regulamentos ambientais mundiais, com mecanismos de execução e a criação de um imposto 
sobre as nações industriais do Norte desenvolvido para ajudar em diversos sistemas de controle de poluição nos países do Sul subdesenvolvido. Sugere, ainda, um regimento que regulamente o comércio global no tocante aos benefícios que a globalização pode trazer para a promoção do desenvolvimento humano, bem como uma regulamentação mundial das normais laborais, prevendo, inclusive, sanções para as empresas que não as respeitem. Por fim, sugere que uma grande variedade de acordos e tratados internacionais poderiam ser incorporados nos ordenamentos jurídicos das nações por meio de ações judiciais e legislativas. Nesse caso, a autora sugere que normas transnacionais sejam devidamente recepcionadas pela legislação estatal.

O sétimo princípio aborda, novamente, a soberania das nações, entretanto, dessa vez, por outro viés. Nussbaum (2004) propõe que a soberania dos estados nacionais seja respeitada, mas, que não seja completamente blindada, uma vez que isso poderia proporcionar maior gravidade às adversidades enfrentadas pelas camadas mais desfavorecidas da população dos país, tais como as mulheres, os negros e a população denominada LGBT (sigla de Lésbicas, Gays, Bissexuais, Travestis, Transexuais e Transgêneros). Para exemplificar tal princípio, questiona-se, até que ponto as instituições e a população do mundo como um todo devem se manter inertes perante grave situação de discriminação de gênero e violência contra a mulher que é constatada em alguns países de forma ainda impune. Nesse caso, a autora afirma que devem ser concentrados e priorizados esforços para os mais desfavorecidos de cada nação.

Reitera, ainda, que tais esforços não podem ser confundidos com sanções coercitivas aplicadas a essas nações, o que feriria gravemente suas soberanias e somente seria justificável em casos extremos de séria violação dos direitos humanos. A ação das instituições e dos indivíduos, para Nussbaum (2004), dever-se-ia concentrar em mobilização política, debates, discussões, argumentação, persuasão e financiamento seletivo.

Ainda neste enfoque de amparar os mais desfavorecidos, vem o oitavo princípio, que, por sua vez, trata do cuidado que a comunidade mundial deve oferecer para os deficientes, doentes e idosos. Sugere, ainda, que modificações (institucionais, estruturais, etc.) sejam feitas para dar maior comodidade aos hipossuficientes dos quais se tratam os princípios sete e oito.

Revista Cidadania e Acesso à Justiça | e-ISSN: 2526-026X | Maranhão | v. 3 | n. 2 | p. 39 - 60 | Jul/Dez. 2017. 
O nono princípio deixa de lado a realidade nacional ou global e adentra nas questões domiciliares. Martha Nussbaum acredita que família é uma esfera muito preciosa, que não deve ser, entretanto, considerada completamente privada do controle do Estado. Tradições milenares de inviolabilidade do lar e a preferência das pessoas por não intervirem em questões relativas a outras famílias, evidenciadas por máximas errôneas como “em briga de marido e mulher ninguém mete a colher”, acabam por prejudicar seriamente as mulheres e por agravar a situação da violência doméstica. Aduz, ainda, que pouco tem feito o Estado para proteger suas mulheres e para garantir que elas e todos os membros da família, em geral, possam desenvolver suas capacidades de acordo com suas preferências e aspirações, e sem serem impedidos por outrem.

O décimo e último princípio proposto por Nussbaum atribui ampla importância ao acesso à educação como fator primordial para o empoderamento das pessoas que se encontram em desfavorecimento. A autora demonstra que as corporações, as organizações não-governamentais e a esfera pública global, em geral, podem fazer muito mais para a promoção do ensino primário e secundário em todas as regiões do globo. Para finalizar sua obra acerca da abordagem das capacidades, destaca-se:

\footnotetext{
Se nosso mundo for um mundo decente no futuro, devemos reconhecer agora que somos cidadãos de um mundo interdependente, mantidos juntos pela comunhão mútua, bem como pela busca da vantagem mútua, pela compaixão e pelo interesse próprio, por amor à dignidade humana de todas as pessoas, mesmo quando não há nada que possamos ganhar ao cooperar com elas. Ou melhor, mesmo quando o que temos de ganhar é a maior de todas as conquistas: a participação em um mundo justo e moralmente decente. (NUSSBAUM, 2004, p. 18).
}

Ademais, Nussbaum também se baseia na teoria de Rawls ao tratar acerca do contrato social e enumerar alguns traços característicos da visão do autor. Primeiramente, o contrato social seria considerado um acordo de vantagem mútua, definida por meio de termos econômicos familiares, entre partidos com poder e recursos equivalentes, não ocorrendo qualquer dominação entre as partes.

Por último, dever-se-ia considerar o Estado-Nação como uma unidade básica, sendo as partes contratantes as responsáveis por direcionar os princípios de tal Estado, os quais seriam capazes de introduzir a vida em cooperação e distanciar as pessoas do seu estado de natureza fazendo com que as relações harmônicas se tornassem cada vez mais comuns e 
possíveis. Dessa forma, conclui-se a partir da ótica de Nussbaum (2004) a inserção do fenômeno concernente ao Comércio Justo nesse movimento pela Justiça Global.

\title{
4 A Justiça Global e o Comércio Justo como Movimento Social
}

Não obstante a Justiça Global representar um conceito (teórico) bastante controvertido em virtude da dificuldade de aplicação foi por intermédio dos Fóruns Sociais Mundiais que se consolidou a proposta.

\begin{abstract}
O movimento de Justiça Global está em formação desde o final da década de 1990 e tornou-se tema de muitos novos estudos. Está sendo analisado como uma reação à globalização neoliberal, uma espécie de "globalização que vem debaixo", um elemento-chave da sociedade civil global e um exemplo da transnacionalização da ação coletiva. Composto por ONGs, movimentos sociais e organizações da sociedade civil, advocacia transnacional, redes, sindicatos, grupos religiosos e ativistas individuais que se opõem ao neoliberalismo e à guerra, o movimento de Justiça Global existe em diferentes graus de coordenação e ativismo em todas as regiões. (MOGHADAM, 2009, p. 91)
\end{abstract}

Tais fóruns serviram para discutir acerca de diversos movimentos sociais engajados rumo à Justiça Global e, dessa feita, também na qualidade de reação ao neoliberalismo e às políticas econômicas responsáveis pelo aumento da desigualdade entre as classes mais ricas e mais pobres do planeta.

\footnotetext{
Os movimentos pela Justiça Global constituem uma séria ameaça para o sistema de dominação que impera, pois vão além da dinâmica anterior das Organizações NãoGovernamentais para o Desenvolvimento (ONGD) que combinavam projetos de desenvolvimento e programas de pressão política reduzidos à elaboração de informes, cartas e visitas a representantes das classes governamentais e empresariais. (DÍAS-SALAZAR, 2003, p. 32)
}

Esses movimentos sociais tinham atuação nas mais diversas áreas da sociedade, abrangendo questões como defesa do meio-ambiente, direitos humanos, feminismo, direitos indígenas, defesa dos direitos trabalhistas, políticas contra a pobreza, luta pela paz e diminuição das desigualdades sociais. Tais processos de transformação social só se tornaram possíveis pelo aparecimento de coletivos que detectaram problemas para o exercício da cidadania. Tais coletivos após a detecção desses problemas buscam solução para os mesmos, inserindo-se nesse contexto os movimentos sociais e algumas organizações não governamentais que hodiernamente se mostram como os principais meios de representação 
cujo objetivo pode ser considerado para a diminuição das desigualdades regionais. Dentre esses movimentos sociais, está o Comércio Justo:

Finalmente tem que se fazer referência às redes internacionais de comércio justo agrupadas na IFTA (Federação Internacional de Comércio Justo) e na NEWS (Rede de Lojas de Comércio Justo). São formas coletivas de consumo responsável que têm dois fins: dirigir a compra a produtos de cooperativas do Sul com códigos de economia social e ecológica e desviá-la daqueles ofertados pelas multinacionais, especialmente nos setores de alimentação, têxtil, material esportivo, etc. (DÍASSALAZAR, 2003, p. 45)

O Comércio Justo significa "uma prática comercial baseada na eficiência econômica, sustentabilidade social e sustentabilidade ecológica [...] o Comércio Justo não é uma capitulação ante a ideologia do mercado". (VAN DER HOFF, 2002, p. 242-243). Segundo a Coordinadora Latinoamericana y del Caribe de Pequeños Productores y Trabajadores de Comercio Justo (CLAC), o Comércio Justo representa:

[...] um movimento social global cujas experiências pioneiras iniciaram em fins de 1940 como respostas alternativas ao fracasso do modelo de comércio convencional para promover padrões produtivos-comerciais responsáveis e sustentáveis, além de oportunidade de desenvolvimento para os pequenos agricultores, camponeses e artesãos em desvantagem econômica e social, relativamente aos atores dominantes no mercado. O Comércio Justo é um modelo comercial que põe no centro os seres humanos e a sustentabilidade social, econômica e ambiental das sociedades, dignificando o trabalho, respeitando o meio ambiente e fomentando uma gestão responsável e sustentável dos recursos naturais.(CLAC, 2017)

Percebe-se, portanto, que não se trata de uma oposição às regras da Organização Mundial de Comércio, mas, de movimento social harmônico com a percepção contemporânea sobre o conceito de Justiça Global. Percebe-se que a clássica forma de realizar o comércio gera situações injustas e difíceis de ser suportadas pelos mais pobres, tanto os produtores como os consumidores entendem que seu trabalho não vai fazer que os mesmos alcancem uma vida digna, daí a proposta trazida pelo Comércio Justo.

Seria uma verdadeira reabilitação do comércio (MARECHAL, 2016), como um instrumento político central, face à notável capacidade para desnaturar 'o mercado':

O Comércio Justo (CJ) levanta a questão de compensação para esses atos que beneficiam toda a sociedade. Economicamente podem ser tratados através de internalização nos preços (o consumidor/o comprador paga) ou de intervenção pública (o contribuinte paga). A resposta à pergunta "Quem vai pagar é o consumidor ou o contribuinte?” é altamente política. Enquanto países do Sul como o Brasil, com o Programa de Aquisição de Alimentos (PAA) e o Programa Nacional

Revista Cidadania e Acesso à Justiça | e-ISSN: 2526-026X | Maranhão | v. 3 | n. 2 | p. 39 - 60 | Jul/Dez. 2017. 
de Alimentação Escolar (PNAE); e, o Equador, assumem uma intervenção pública forte, a maioria dos países do Norte abrem mão da soberania alimentar. As respostas estão muito além da aplicação de regras comerciais. Elas devem caber em um corpo político coerente. Entre as teorias disponíveis, as que tratam da economia social ou do terceiro setor, as teorias libertárias são as menos impotentes para associar CJ e consistência política. E, sem essa referência, a ação permanecerá órfã e exposta aos ventos dominantes do dogmatismo liberal (MARECHAL, 2016, p. 11).

Eis que o dilema trazido acerca de uma feição política do Comércio Justo que deveria ser adotado a fim de que não houvesse necessidade de implantação de políticas públicas assistenciais, demonstra a necessidade de conceituação que tenha a ideia de movimento social devidamente inserida:

O Comércio Justo (CJ) pode definir-se, em traços gerais, como movimento social que visa promover formas de desenvolvimento e de consumo sustentáveis assentes na melhoria da qualidade de vida dos pequenos produtores dos países do hemisfério Sul, através da atividade comercial. Nesta medida, o CJ é também uma forma comercial alternativa que valoriza as condições sociais de produção, distribuição e consumo. (COELHO, 2015, p. 15)

Ao analisar tal definição é possível constatar a inserção do Comércio Justo como movimento social que se propõe como uma alternativa ao comércio tradicional e que valoriza as condições sociais tanto por parte do produtor, como do distribuidor; e, enfatiza também a figura do consumidor. Essa ênfase no consumidor dá a entender o relevante papel que esse tem para que se realize a verdadeira Justiça Global, porque é no consumo associado ao Comércio Justo que efetivamente se representa um ato de justiça. Afinal, o que o consumidor deve levar em conta não é somente o melhor preço para a aquisição do produto desejado e sim algo que tenha relação com responsabilidade pelo outro (alteridade) ou mesmo respeito pelos direitos humanos.

Na sociedade globalizada o consumo é algo que faz parte do cotidiano, até porque estimula sentimentos agregados à imagem, às necessidades, ou mesmo ao bem-estar por parte de todos. Contudo, possui em seu bojo aspectos que servem para estimular e disfarçar as desigualdades sociais existentes. Surge, assim, o consumo como proposta ética ou outro tipo de consumo que não deve estimular a desigualdade social e que pode ser denominado como consumo responsável. Em síntese, configura a existência de um consumidor cujo conhecimento que possui o torna cônscio de que possui um papel na sociedade. 
De acordo com Coelho (2015), a noção de consumo responsável aparece como um procedimento de intervenção, uma forma de expressão de cidadania que espelha o que cada indivíduo pode fazer para melhorar o mundo em que vive, a partir de suas atitudes cotidianas. Segundo o autor, trata-se de proposta alternativa ao atual modelo de desenvolvimento e consumo, fortemente caracterizado por assimetrias e falta de solidariedade. Assim, a mobilização popular é extremamente necessária para essas questões ligadas ao consumo. Por outro lado, é necessário que cada vez mais haja sensibilização e adoção de novas práticas com o intuito de coibir o modelo atual, insustentável e nocivo para as futuras gerações.

Essa mobilização demanda a formação de redes, caracterizadas pela participação de ONGs, cooperativas, associações que não possuem fins lucrativos, ente outros atores, especialmente visando à aproximação dos camponeses e artesãos do Sul com os consumidores do Norte sempre com ênfase em valores morais e sociais. Conforme Coelho (2015), cumpre promover a justiça social, a proteção ambiental, a igualdade de gênero e a equidade social, em detrimento dos valores tipicamente associados à racionalidade econômica que busca a acumulação incessante de lucro. Coelho (2015) enfatiza que o Comércio Justo por si traz regras comerciais próprias, seguindo o entendimento da existência de um direito transnacional que regula as relações comerciais entre essas redes. “O CJ estabelece regras comerciais que têm em conta desequilíbrios entre países ricos e países pobres, e através dessas regras procura reequilibrar essas assimetrias.”

Conforme as ações informacionais realizadas pelas redes é importante entender que o consumidor que adquire um produto do Comércio Justo está exercendo um ato de justiça que reflete a solidariedade para com os produtores do Terceiro Mundo, tornando-se não só uma forma de consumo alternativa, mas também algo inerente à política internacional.

Isso é importante, porque a equação das compras comerciais justas e dos atos de
justiça tem sido crucial para o dinamismo da campanha de comércio justo, o que
talvez explique por que também se refletiu tão consistentemente na literatura
acadêmica sobre o assunto.[...] A questão do Comércio Justo é muito uma questão
da política internacional, na medida em que toda sua essência se baseia na premissa
de que as dimensões morais das relações de intercâmbio modernas se estendem para
além das fronteiras nacionais. (WATSON, 2007, p. 266; 264)

Em síntese, é complexo e mesmo inviável querer cercar o fenômeno somente por uma dimensão, afinal, comporta diferentes enfoques. Como expressa a CLAC (2017), aqueles que estimulam o fenômeno partem de distintas combinações, relativamente ao eixo (Sul - 
Norte, Sul - Sul, Norte - Norte), à região geográfica almejada (no Sul ou no Norte), em níveis de alcance dos consumidores (local e/ou nacional e/ou internacional), a partir de distintos modelos de certificação (por terceiros, participativos, sem certificação), etc. De natureza multidimensional, o Comércio Justo exige reflexões de diversas áreas do conhecimento.

\section{Conclusão}

O estudo do Comércio Justo possui uma inclinação a demonstrar que se trata de um ato de solidariedade dos consumidores do Norte que adquirem o que é produzido pelos produtores do Sul, espécie de assistencialismo do qual dependem os agricultores e artesãos. Essa é uma visão equivocada dos países do Norte que depois de criarem a pobreza, agora querem acabar com ela. Segundo visões progressistas, oriundas da América Latina, trata-se de relações de troca, pautadas por sustentabilidade em consonância com regras no âmbito do comércio convencional. Desse ponto de vista, representa um movimento social visando à Justiça Global.

Tal movimento encontra alicerces teóricos consistentes e preconizados por reconhecidos autores - com destaque para Pogge, Beitz e Nussbaum - que defendem a necessidade de adoção de uma Justiça Global para que sejam reduzidas as desigualdades sociais. Enquanto os dois primeiros investigadores defendem a adoção de um Pacto Global, a terceira privilegia o estímulo para que cada indivíduo possa exercer plenamente suas capacidades.

Essas linhas de pensamento, de qualquer forma, formam um uníssono quanto ao propósito do Comércio Justo servir de ferramenta à adoção de um pacto entre os produtores do Sul e dos consumidores do Norte, no qual se viabilizassem regras justas que incluíssem o respeito ao meio ambiente e às relações de trabalho. Sob esse feitio, promover-se-ia um consumo responsável e justificado. Além disso, seria possível efetivar a 'abordagem de capacidades' de Nussbaum, pelo fato dos artesãos e pequenos agricultores escolherem seus destinos de acordo com a concretização de mercado consumidor para os seus produtos.

Tais conceitos são hábeis para que se vislumbre a questão da Justiça Global como uma teoria de justiça distributiva e que possui diversas formas para se efetivar, pois se torna um objetivo a ser alcançado por diversos movimentos sociais cada vez mais presentes e com os mais variados objetivos, da proteção ao meio ambiente aos direitos de LGBTs, do respeito 
às relações de trabalho às instituições que pregam uma paz mundial, da proteção às relações de gênero ao consumo responsável de produtos.

Por fim, chega-se à constatação que realmente o Comércio Justo se insere no conceito de movimento social que prega o consumo responsável e solidário daquilo que é produzido pelos agricultores e artesãos do Sul e que essa prática se mostra como uma forma de se reduzir as desigualdades sociais surgidas da globalização e cujo sucesso é a demonstração cabal da prática de Justiça Global que propicia a utilização das capacidades dos indivíduos.

\section{Referências}

BEITZ, Charles R. La idea de los derechos humanos. Local: Madrid Marcial Pons, 2012.

CASTELLS, Manuel. A era da informação: economia, sociedade e cultura. 6.ed. Tradução de Roneide Venancio Majer. São Paulo: Paz e Terra, 2011.

CLAC (Coordinadora Latinoamericana y del Caribe de Pequeños Productores y Trabajadores de Comercio Justo). Qué es la CLAC. Disponível em: <http://www. http://claccomerciojusto.org/que-es-la-clac/quienes-somos/> Acesso em: 10/06/2017.

COELHO, Sandra Lima. Sobre a justiça no comércio e as escolhas morais de consumo: o caso dos consumidores... Sociologia. Revista da Faculdade de Letras da Universidade do Porto, Número temático - Práticas de consumo: valores e orientações, 2015, p. 15-40

COLLSTE, Göran. Globalisation and Global Justice. De Ethica. A Journal of Philosophical, Theological and Applied Ethics, Vol. 3:1, 2016.

DÍAZ-SALAZAR, Rafael (Org.). Justicia global: las alternativas de los movimientos del Foro de Porto Alegre. 2.ed. Barcelona: Icaria Editorial; Intermón Oxfan, 2003.

FRIEDEN, Jeffry A.. Capitalismo global. Tradução de Vivian Mannheimer. Rio de Janeiro: Jorge Zahar, 2008.

MARÉCHAL, Gilles. Entre Global e Local: caminhos e descaminhos do comércio justo. In: STELZER, Joana; GOMES, Rosemary. Comércio justo e solidário no Brasil e na América Latina. Florianópolis: Departamento de Ciências da Administração, 2016.

MOGHADAM, Valentine M., Globalization and social movements : Islamism, feminism, and the global justice movement. [s/l] Rowman \& Littlefield Publishers Inc., 2009.

NUSSBAUM, Martha. Beyond The Social Contract: Capabilities and Global Justice Oxford: Oxford Development Studies, 2004. 
ODES (OBSERVATÓRIO DAS DESIGUALDADES). Relatório IDH - 2015. Disponível em: < https://observatorio-das-desigualdades.com/2017/03/29/o-desenvolvimento-humanoidh-em-2015-no-mundo-e-em-portugal/ > Acesso em: 10/08/2017.

POGGE, Thomas. Real World Justice, The Journal of Ethics, n. 9, 2005, pp. 29-53.

POGGE, Thomas. World Poverty and Human Rights. Cambridge: Polity Press, 2002.

RAWLS, John. The Law of Peoples. Cambridge: Harvard University Press, 1999.

STELZER, Joana; GONCALVES, Everton das Neves. Fair Trade em redes de colaboração solidária: possibilidades comerciais justas em um emergente espaço transnacional. In: Paulo Emílio Vauthier Borges de Macedo; Bruno Vianna. (Org.). Direito Internacional II. Florianópolis - SC: CONPEDI, 2014, v. 1, p. 269-297.

TRADINGECONOMICS. Dados 2015 Tradingeconomics. Disponível em: < https://pt.tradingeconomics.com/country-list/gdp-per-capita> Acesso em: 02/08/2017.

VAN DER HOFF, Frans; ROOZEN, Nico. La Aventura del Comercio Justo: una alternativa de globalización, por los fundadores de Max Havelaar. Tradução de Michel Janssen. México, DF: El Atajo, 2002.

WATSON, Matthew (2007), Trade Justice and Individual Consumption Choices: Adam Smith's spectator theory and the moral constitution of the fair trade consumer, European Journal of International Relations, 13 (2), pp. 263-288.

WILLIAMSON, Edwin. História da América Latina. Tradução de Patrícia Xavier. Lisboa (Portugal): Edições 70, 2012. 